\title{
O DOCENTE-PESQUISADOR: \\ A INVESTIGAÇÃO-AÇÃO COMO UMA FORMA VÁLIDA DE GERAÇÃO DE CONHECIMENTOS ${ }^{i}$
}

\author{
Gary L. Anderson ${ }^{\mathrm{ii}}$ \\ Kathryn Herrii
}

\begin{abstract}
Resumo: O presente texto discute a questão da pesquisa em educação em face do compromisso político de gerar conhecimentos e potencializar a transformação das práticas pedagógicas. Destaca alguns tipos de investigação que vêm sendo realizados na, sobre e com a escola e sublinha o desafio bem como a importância da realização de pesquisas com os professores, numa perspectiva de investigação-ação participativa. Traça alguns critérios de validade para a pesquisa e conclui com algumas reflexões a respeito da relevância da investigação-ação participativa envolvendo universidade e escola básica como um fator importante para o desenvolvimento profissional dos docentes. Por fim, enfatiza a narração e a etnografia como modos de os professores documentarem e repensarem suas práticas e o contexto sócio-cultural e econômico em que estão inseridos.
\end{abstract}

Palavras-chave: Investigação-ação; Participação; Pesquisa docente.

\section{EL DOCENTE INVESTIGADOR: \\ LA INVESTIGACIÓN-ACCIÓN COMO UNA FORMA VÁLIDA DE GENERACIÓN DE CONOCIMIENTOS}

Resumen: En este trabajo se analiza el tema de la investigación educativa frente al compromiso político para generar conocimiento y potencializar la transformación de las prácticas de enseñanza. En este sentido, se destacan algunos tipos de investigación que se llevan a cabo en, sobre y con la escuela y subraya el desafío y la importancia de la realización de investigaciones con los maestros en una perspectiva de investigación-acción participativa. Esboza algunos criterios de validez para la investigación y concluye con algunas reflexiones sobre la importancia de la investigación-acción participativa que involucra la universidad y la escuela como un factor importante para el desarrollo profesional de los docentes. Por último, enfatiza la narración y la etnografía como formas de documentar y repensar las prácticas y el contexto sociocultural, económico de la escuela.

Palabras clave: Investigación-acción; Participación; Investigación docente.

Tem-se escrito muito acerca da investigação-ação como uma metodologia com a potencialidade não apenas de melhorar ou transformar as práticas, mas também de gerar conhecimentos, tanto locais - o saber popular - quanto públicos - o saber científico. Sem dúvida, diferentes disciplinas e campos de prática profissional se apropriaram da 
investigação-ação de diversas maneiras. Internacionalmente, poucos escritos ou estudos foram traduzidos, isolando pesquisadores tanto por disciplinas como também por idioma. $\mathrm{O}$ resultado disso tem sido uma fragmentação da bibliografia sobre o tema e sobre as formas de compreender a investigação-ação.

Em campos como a psicologia comunitária, o desenvolvimento internacional e a saúde pública, a investigação-ação implica que um investigador universitário entre em uma instituição ou comunidade para fazer investigação-ação junto com e não sobre os participantes. Este tipo de investigação-ação se chama investigação-ação participativa (IAP) e provém da tradição latino-americana de Paulo Freire (1968) e Orlando Farls Borda (1991). Freire agrega uma dimensão emancipatória à IAP com a ideia de começar a investigação não desde as perguntas do pesquisador, mas desde os "temas geradores" dos participantes.

Alguns investigadores aplicaram essa metodologia ao desenvolvimento curricular e profissional e à avaliação educativa (ACHILLI, 2000; BATALLÁN; GARCÍA, 1988; SIRVENT, 1993). Ao mesmo tempo - e sobretudo em campos como a educação, a enfermagem e o trabalho social - se desenvolveu um tipo de investigação-ação realizada pelos mesmos docentes ou profissionais dentro de suas próprias escolas, salas de aula, hospitais, universidades ou agências sociais (ELLIOTT, 1993; LATORRE, 2003; LÓPEZ GORRIZ, 1993; MARTÍNEZ, 2000; OLSON, 1991; PÉREZ GÓMEZ, 1990).

O que a IAP e a investigação-ação feita por profissionais (investigação-docente) têm em comum é a ideia de gerar conhecimentos a partir das ações ou intervenções em instituições e comunidades. Distinguem-se pela posição do pesquisador frente ao cenário social que estuda. A IAP está conduzida de fora por um pesquisador universitário, muitas vezes convidado ou contratado pela própria instituição que está estudando. A investigação-ação feita por docentes ou profissionais está conduzida pelos próprios membros das instituições ou comunidades. Este último tipo de investigação-ação - menos analisado nos escritos acadêmicos na América Latina sobre a investigação-ação - apresenta uma série de dilemas epistemológicos, éticos e políticos distintos dos da IAP (HERR; ANDERSON, 2005). Por isso, neste trabalho queremos enfocar a investigação-ação feita desde dentro do cenário da pesquisa pelos próprios profissionais e, mais especificamente, por docentes e professores.

A investigação-ação no campo da educação é utilizada principalmente como uma forma de desenvolvimento profissional. Como tal, às vezes é difícil distinguir entre a reflexão profissional (sobre a própria prática) e a investigação-ação. A distinção se encontra no grau de 
intencionalidade e sistematização da reflexão. A investigação-ação requer uma espiral de ciclos de planejamento, ação, observação e reflexão. Os resultados de um ciclo de investigação servem como ponto de partida para o seguinte, e o conhecimento produzido é relevante para a resolução de problemas locais e a aprendizagem profissional dos docentes/investigadores. Quando é feita em coletivo, a investigação-ação pode também resultar na aprendizagem organizacional (ARGYRIS; SHÖN, 1978) e, a partir de pontos de vistas mais radicais, produzir transformação social (FREIRE, 1978). Em muitos casos, os docentes fazem cursos sobre metodologias para recolher e analisar dados, ou pesquisa sobre métodos relevantes.

$\mathrm{Na}$ verdade, poucos profissionais fazem investigação com a intenção de difundi-la para além do cenário local. Sem dúvidas, os conhecimentos locais produzidos podem melhorar a compreensão pública acerca da reforma educativa, tanto na dimensão da sala de aula quanto da própria escola. Estes conhecimentos poderiam fazer parte de uma teoria da mudança tradicional - geração, disseminação e utilização de conhecimentos - empregada por acadêmicos universitários - com pouca eficácia -, ou poderiam se constituir em outra fonte de conhecimento público passível de ser difundida através dos sindicatos ou das agências educacionais estaduais ou municipais (ZEICHNER, 1993).

Ainda que a investigação-ação tenha se legitimado como processo de desenvolvimento profissional e organizacional e para a geração de conhecimentos locais (limitados à melhora da própria prática), ainda lhe falta legitimidade acadêmica no tocante à sua capacidade de contribuir com o debate público sobre a reforma de práticas pedagógicas e da gestão organizacional. Para muitos pesquisadores acadêmicos, a ideia de levar a sério conhecimentos produzidos por professores desprestigia seu papel de experts $^{\text {iv }}$. Ainda muitos acadêmicos que promovem a pedagogia crítica e consideram o professor como intelectual, mantêm a dicotomia entre os que produzem conhecimentos e quem os utilizam (GIROUX, 1990). Que os professores participem em estudos de IAP conduzidos por um pesquisador é uma coisa; que o professor tenha a audácia de se considerar pesquisador é outra.

A investigação docente é nova. Tem uma extensa trajetória que, na Argentina, inclui o trabalho do professor Luis Iglesias, que fez investigação em sua sala de aula por muitos anos e logo publicou vários livros (SANTILLÁN, 2002). Investigadores como Rodrigo Vera, Graciela Batallán e Elena Achilli nos anos 1970 elaboraram as “oficinas de educadores", baseando-se nos grupos operativos de Pichon-Rivière e a conscientização de Paulo Freire. 
Inclusive, há bastante literatura sobre o uso da investigação docente como veículo para a formação inicial e contínua do professor. O menos comum é a proposta de uma discussão acerca da potencialidade de uma investigação docente para reconstruir a base de conhecimentos públicos sobre processos de ensino/aprendizagem e gestão escolar. Enríquez (2004) disse em relação a essa potencialidade:

(...) É desde a prática, entendida como síntese de pensamento e ação, de onde se pode realizar uma reflexão sistemática e uma análise profunda que desemboquem na formulação de novos constructos teóricos. Portanto, a produção de conhecimento efetuada por docentes implicados no processo pedagógico é o que vai permitir a apreensão profunda da complexa e cambiante realidade educativa (p. 3).

Este artigo busca apresentar uma série de critérios de "validade" ou "confiabilidade" para a investigação-ação e uma discussão de como a posição do pesquisador determina o grau de "validade" do estudo, com o fim de legitimar a investigação-ação realizada por docentes dentro das escolas.

\section{Os termos do debate sobre a investigação-ação}

Depois de um longo debate com investigadores positivistas, a pesquisa "qualitativa" ou "etnográfica" alcançou certa legitimidade dentro das ciências sociais e a "ciência" da educação. Sem dúvida, o intenso debate a propósito da legitimidade da investigação-ação está apenas começando. Infelizmente, a legitimidade alcançada pela pesquisa qualitativa não abarca a investigação-ação, porque muitos pesquisadores - tanto quantitativos como qualitativos - a veem como uma forma de conhecimento pouco rigoroso.

Nos Estados Unidos, Huberman (1996) criticou Cochran-Smith e Lytle (1998) e outros que defendem a investigação docente, alegando que a investigação-ação não pode contribuir com conhecimentos para o campo da educação. Alguns concedem legitimidade à investigação-ação, mas a relegam a uma categoria à parte, definindo-a como conhecimento "prático" - gerado em escolas - ao invés de conhecimento "formal" - gerado nas universidades -, e insistem em uma separação estrita entre a investigação educativa e a prática educativa (FENSTERMACHER, 1994; HUBERMAN, 1996; RICHARDSON, 1994). 
Por exemplo, Richardson (1994) define a investigação-ação como "investigaçãoprática" que se foca exclusivamente na melhoria das práticas. Em relação à "investigação prática”, Fenstermacher (1994) insiste que o conhecimento prático resulta da participação em e na reflexão sobre a ação e a experiência; está limitada pela situação ou o contexto local, pode ou não ser capaz de expressão imediata - verbal ou escrita -, e sua preocupação está restrita a como fazer coisas, o lugar e o momento adequado para fazê-las, ou como ver e interpretar os eventos relacionados com as ações realizadas pelo professor (p. 12).

Em sua resposta, Cochran-Smith e Lytle (1998) rejeitam a dicotomia proposta entre conhecimento formal e prático porque implica (ela) uma limitação desnecessária à natureza do ensino e da investigação-ação. O que eles sublinham é:

(...) como as ações dos professores estão influenciadas pela complexidade de suas formas de entender a cultura, a classe social e o gênero dos alunos, os problemas sociais, as instituições, as comunidades, os materiais, os textos e o currículo, e por suas ideias acerca de como aprendem os alunos. Na investigação-ação, os docentes trabalham juntos para desenvolver e alterar seus interrogantes e marcos interpretativos, informados não apenas por uma análise da situação imediata e pela situação de seus alunos específicos (aos quais ensinam e aos quais ensinaram), mas também pelos múltiplos contextos - social, político, histórico e cultural - dentro dos quais ensinam (p. 24).

Connelly e Clandinnin (1995), por sua vez, comentam que

(...) o conhecimento acadêmico chega ao docente como uma retórica de conclusões em forma de conhecimentos teóricos e proposicionais, sem entender que o mundo do docente é pessoal, contextual, subjetivo, temporal, histórico e relacional (p. 5).

Assim como o fornecimento de critérios preliminares para a investigação docente é necessária, os critérios válidos para os investigadores acadêmicos também precisam ser claros para o professor. Por exemplo, um etnógrafo educativo precisa passar um tempo prolongado no campo para ter dados confiáveis, entretanto, que sentido tem esse critério para um docente que passa anos em sua sala de aula? Segundo Anderson, Herr e Nihlin (1994), o dilema do professor é diferente do dilema do etnógrafo.

O pesquisador acadêmico precisa entender a perspectiva do "nativo" sem se identificar muito, para não perder seu distanciamento. O professor já tem a perspectiva do "nativo", 
porém, precisa se esforçar para tomar certo distanciamento dos aspectos naturalizados de sua prática (Ibid, p. 27).

Para que a investigação-ação seja aceita como metodologia legítima, os pesquisadores terão de formular alguns critérios de validade. Isso não quer dizer que tenham de se justificar através dos mesmos critérios da investigação tradicional, mas deverão convencer aos outros pesquisadores de que este tipo de pesquisa é capaz de produzir conhecimentos importantes e válidos dentro de critérios coerentes com sua metodologia. Estes critérios devem responder aos propósitos e condições especiais (por exemplo, a posição do investigador, a centralidade da ação, etc.) deste tipo de investigação.

$\mathrm{O}$ fato de ser professor requer certa apreciação das diferenças entre um trabalho rigoroso e outro pouco rigoroso, entre uma análise e a mera opinião. Os professores aplicam estes critérios ao trabalho de seus alunos e sabem empregá-lo em suas próprias pesquisas e às de seus colegas. De fato, como indicaremos mais adiante, o projeto para definir critérios de qualidade para a investigação-ação já começou.

\section{Critérios para a "validade" ou "confiabilidade" da investigação docente}

Os docentes-investigadores fazem investigação com múltiplos fins. Se o objetivo é produzir conhecimentos para "se atualizarem" dentro da área de estudo - por exemplo, para resolver problemas na sala de aula - o conceito de "validade" tem mais a ver com a utilidade dos dados para a resolução do problema. Se o fim da investigação é a disseminação de conhecimentos para além do campo da pesquisa, então o conceito de "validade" concerne não apenas à utilidade do conhecimento, mas com sua capacidade de fazer uma contribuição a uma comunidade maior, tanto de prática como de investigação. No segundo caso, o docenteinvestigador pretende disseminar seus resultados por meio de uma tese, apresentações em congressos ou artigos acadêmicos.

\section{A validade da resolução do problema}

Uma maneira de determinar a validade da investigação-ação é perguntar-se até que ponto as ações conduziram à resolução do problema estabelecido - no estudo - ou a um 
entendimento mais profundo do problema. Ou seja, até que ponto se resolveu o problema ou dilema profissional dentro de um contexto específico e com certos parâmetros, limitações e possibilidades? A este tipo de validade chamamos de validade da resolução do problema. Alguns estudos de investigação-ação terminam com um diagnóstico do problema ou a implementação de uma única estratégia de solução, sem importar se o problema se resolve ou não. Assim, a validade dos resultados depende de uma resolução satisfatória do problema.

Sem dúvida, e de acordo com a "validade democrática" que desenvolveremos mais adiante, surge a pergunta: satisfatória para quem? A validade de resultados reconhece o fato de que a investigação-ação não só resolve problemas, mas também os reconceitualiza de uma forma mais complexa, conduzindo a um novo ciclo de investigação.

\section{A validade do processo}

A validade do processo questiona até que ponto os problemas em investigação são entendidos e resolvidos de uma maneira que permita a aprendizagem contínua do indivíduo ou sistema. Então, a validade de resultados dependerá da validade do processo à medida que, se o processo metodológico for superficial ou incorreto, os resultados o refletirão. Por processo não entendemos somente os métodos de recolhimento dos dados, mas a espiral de ciclos de reflexão que inclui a problematização das práticas ou problemas em estudo. De outro modo, a investigação-ação corre o risco de justificar práticas ou meramente reproduzi-las, e pode ser cooptada institucionalmente. Os ciclos de reflexão devem incluir uma análise das concepções prévias que se encontram detrás das práticas e a definição dos supostos "problemas" (ARGYRIS; SCHÖN, 1978).

Quando se trata da validade do processo, a investigação-ação pode lançar mão de alguns critérios da investigação qualitativa. A triangulação, ou a inclusão de múltiplas perspectivas - docentes, estudantes e pais, por exemplo - torna menos provável que os resultados estejam tendencionados por uma única perspectiva. A triangulação também pode referir-se à inclusão de múltiplos métodos - por exemplo, observações, diários e entrevistas -, não se limitando a uma única fonte de dados.

Em geral, pensamos na investigação-ação como uma metodologia das ciências sociais, sem dúvida, o auto-estudo, a auto-etnografia ou o relato docente ${ }^{\mathrm{v}}$ podem requerer métodos 
narrativos tomados das humanidades. O estudo das práticas docentes pode demandar um enfoque sobre a vida pessoal e profissional do mesmo investigador/docente. A investigação narrativa tem outros critérios de validade para avaliar uma narrativa empírica (não ficção). Os canadenses Connelly e Clandinin (1990) desenvolveram critérios de validade para a investigação narrativa e, na Argentina, Suárez e Ochoa (2005) trabalham sobre como a experiência e a memória docentes podem ser tratadas como "dados" através de várias repetições de uma narração.

\section{A validade democrática}

A validade democrática se refere ao grau de colaboração do investigador com todos os participantes afetados pelo problema em análise. Se a investigação não é colaborativa, de que maneira se têm em conta as múltiplas perspectivas e interesses dos implicados? Assim, é importante que os docentes ou diretores não utilizem a investigação-ação para encontrar soluções que os favoreça a custa dos outros, como, por exemplo, pais e alunos. Os pais e os alunos são vistos como parte da comunidade escolar ou da sala de aula, ou são vistos como externos a essa comunidade? Enquanto a validade do processo depende da inclusão de múltiplas perspectivas para a triangulação, a validade democrática requer a inclusão como um assunto de ética e justiça.

Outra versão da validade democrática é o que Cunningham (1983) chamou de "validade local", na qual as perguntas emergem de um contexto específico e as soluções são apropriadas e este contexto. Alguns chamam isso de relevância, aplicabilidade ou viabilidade, ou como determinamos a relevância dos resultados para as necessidades do contexto local.

\section{A validade catalítica}

A "validade catalítica" se refere ao grau em que o processo da investigação reorienta e motiva aos participantes a analisar e entender a realidade com o fim de transformá-la (LATHER, 1986, p. 272). Parecido com o conceito de "conscientização" de Freire, a validade catalítica requer uma espécie de co-aprendizagem na qual tanto o investigador quanto os participantes cheguem a reorientar sua forma de entender o mundo da prática e da vida social. 
É importante manter um diário que documente este processo de reorientação e das ações que provoca.

Retomamos mais adiante este tema na seção sobre conhecimento e interesse, sobretudo em relação ao que Jürgen Habermas (1971) chamou de conhecimento emancipador. A propósito, alguns pesquisadores falam da capacidade da investigação crítica de "dar voz aos oprimidos" ou "recuperar o conhecimento subjugado". Ignacio Rivas Flores (2007) expõe como a investigação biográfica do docente pode ingenuamente colocar "a voz docente" em um pedestal. Neste sentido, [ele] disse:

(...) desde estas dimensões, "dar voz aos participantes" não é simplesmente fazer com que estes falem acerca de si mesmos, fazendo uma descrição de sua vida e seus pensamentos. Isso seria um conhecimento que poderíamos denominar como "inocente" ou "ingênuo", à medida que não compromete os princípios sobre os quais se sustentam essas descrições. De alguma forma, há que [se] chegar a uma violência epistêmica que leve os participantes a se questionarem sobre o que eles mesmos dizem - e o interpretem como uma expressão dos contextos sociais, políticos, econômicos e morais nos quais se formaram e a experiência nos mesmos (...).

Mas aqui também se corre o risco de substituir o conhecimento ingênuo do docente pelo conhecimento ingênuo do pesquisador, sobretudo se este último tem pouca experiência com a prática docente. Tanto o investigador/participante quanto o docente/participante devem se questionar para alcançar a validade catalítica.

\section{A validade dialógica}

A investigação educativa que se publica em revistas acadêmicas passa por um processo de avaliação de pares. Para ser publicado, um artigo tem de ser avaliado por dois ou três pesquisadores que são especialistas na metodologia e no conteúdo de estudo. Muitas revistas acadêmicas têm também fóruns de debate onde os pesquisadores podem dialogar entre si. Ainda que os docentes precisem de fóruns deste tipo, é cada vez mais comum que os docentes investigadores se juntem em oficinas nas quais realizam estudos colaborativos ou buscam dialogar com outros docentes. Como mencionamos acima, na Argentina há uma rica tradição de oficinas de educadores promovidas por etnógrafos como Rodrigo Vera, Graciela Batallán e Elena Achili, entre outros. Nos Estados Unidos o conceito de comunidade de 
aprendizagem compostas por docentes se refere à investigação colaborativa tanto quanto ao desenvolvimento profissional.

Na Inglaterra, Lomax, Woodward e Parker (1996) estabelecem a importância do que chamam "reuniões de validação", nas quais defendem os resultados dos estudos frente a um grupo de amigos críticos. Bone (1996), um diretor de escola que fez um estudo de investigação-ação para sua tese, descreve uma reunião de validação:

Convidei três pessoas: meu vice-diretor, um docente e um conhecido que trabalhava de consultor. Selecionei meus "amigos críticos" para ter uma variedade de reações a meu estudo. Me ajudaram a refletir sobre minha prática e validar os resultados de minha investigação (p. 23).

Para promover a validade democrática e dialógica, alguns insistem em que a investigação-ação tem que ser participativa (CARR; KEMMIS, 1986). Outros requerem somente que o docente reflita sistematicamente com outras pessoas, ou que trabalhe com um amigo crítico que tenha familiaridade com a escola e possa servir de "advogado do diabo", sugerindo explicações alternativas dos dados.

Quando se obtém a validade dialógica, os estudos de investigação podem alcançar o que Meyers (1985) chama de "uma consonância com as instituições da comunidade docente, tanto na definição dos problemas quanto nos resultados" (p. 5).

Em conclusão, não há uma definição comum de validade em investigação-ação. Todas as definições são tentativas e em fluxo. Estamos de acordo com Connelly e Clandinin (1990), que dizem:

Pensamos que uma variedade de critérios, segundo as circunstâncias, será a norma no futuro. Enquanto isso, cada investigador terá de buscar e defender os critérios que se aplicam melhor a sua situação (p. 7).

Os critérios de validade que elaboramos servem tanto para a investigação-docente quanto para a Investigação-Ação Participativa (IAP), mas a ênfase relativa entre os critérios varia de acordo com a posição do pesquisador.

\section{Posições Múltiplas}


$\mathrm{Na}$ investigação-ação, a posição do investigador determina problemas éticos, políticos e de validade. Há pelo menos três maneiras de se pensar na posição na investigação:

1) Investigar de dentro ou de fora do cenário social (HERR; ANDERSON, 2005).

2) Posição na hierarquia ou nível de poder informal (ANDERSON; JONES, 2000).

3) Posição frente a indivíduos e grupos de outra classe social, raça, gênero, religião, idade, etc. (ANZALDÚA, 1987; COLLINS, 1990).

Collins (1990) capta a complexidade da noção de interior/exterior quando sugere que a localização de alguém em uma organização cria múltiplas perspectivas sobre a realidade. Algumas pessoas são parte do cenário social, mas, ao mesmo tempo, não são, porque são marginalizadas e por isso observam as contradições entre as condutas e as ideologias dos grupos dominantes (COLLINS, 1990, p. 11). Por exemplo, o saber docente é um saber subjugado, no sentido de que as decisões educativas tomadas sobre as reformas escolares e o trabalho docente se adotam, em geral, sem considerar o saber docente, o que faz com que muitas dessas reformas fracassem. Contudo, o saber estudantil é ainda mais subjugado e os docentes, ao tomar decisões pedagógicas e administrativas, poucas vezes levam em conta o saber do estudante sobre sua vida, interesse e formas de aprender.

Collins sustenta que os marginalizados têm um conhecimento especial, subjugado, que proporciona um ponto de vista único acerca deles mesmo e da sociedade. Por exemplo, as mulheres em uma organização dominada por homens podem ser hábeis observadoras da cultura masculina enquanto vivem ${ }^{1}$ suas interações cotidianas com os colegas. $\mathrm{O}$ conhecimento que possuem, neste caso, não difere do outro exemplo que oferece Collins, sobre os escravos negros norte-americanos que tinham um "conhecimento especial" dos brancos, posto que sua sobrevivência dependia de que conhecessem essa cultura. O grupo dominante, sem dúvida, não tem semelhante obrigação. Hoje em dia, por exemplo, em muitas províncias - tanto na Argentina quanto nos Estados Unidos -, o saber indígena é desconhecido e pouco respeitado pelas escolas.

Como Foucault precisa, os saberes subjugados pertencem aos que estão suficientemente fora da corrente principal de uma organização ou de uma entidade, talvez localizados na base da hierarquia institucional. Este conhecimento especializado pode

\footnotetext{
${ }^{1} \mathrm{O}$ autor utiliza o verbo "atravessar": mientras atraviesan sus interaciones cotidianas... Em busca de um sentido mais adequado em nossa língua, optamos pelo emprego do verbo "viver".
} 
contribuir para a aprendizagem organizacional ou, pelo contrário, ser considerado como uma ameaça para a manutenção da cultura de uma instituição. Mas cada um de nós, como pesquisadores, ocupa posições múltiplas que se entrecruzam e criam lealdades e alianças que estão em conflito dentro de nosso cenário de investigação (COLLINS, 1990, p. 11).

Em certos espaços onde nos incluímos como iguais podemos, simultaneamente, identificarmo-nos como diferentes em alguns aspectos, em particular em dimensões como a raça, classe social, gênero ou orientação sexual. Estas incluem a visão de mundo que cada um leva à instituição, em termos de crença política ou ideológica, assim como assunções culturais. Cada uma destas dimensões entra na construção da "realidade" que se captura na investigação. Sugerimos que nossa obrigação como pesquisadores é interrogar nossas próprias posições em relação com a pergunta em estudo. Nossa capacidade de tornar explícitas as tensões que experimentamos como investigadores, em nossos múltiplos papéis e categorias, nos permite tornar mais complexa a compreensão do espaço de estudo e das perguntas em investigação.

Quadro 1: Contínuo de posição na investigação-ação (adaptada de Herr e Anderson, 2005)

\begin{tabular}{|l|l|l|l|}
\hline \multicolumn{1}{|c|}{$\begin{array}{c}\text { Posição do } \\
\text { Investigador }\end{array}$} & \multicolumn{1}{|c|}{$\begin{array}{c}\text { Critérios de } \\
\text { Validade }\end{array}$} & \multicolumn{1}{c|}{ Contribui para... } & \multicolumn{1}{c|}{ Tradições } \\
\hline $\begin{array}{l}\text { 1. Desde dentro } \\
\text { (o investigador } \\
\text { estuda a si } \\
\text { mesmo ou a sua } \\
\text { prática) }\end{array}$ & $\begin{array}{l}\text { Herr; Anderson } \\
\text { (2005); Bullough; } \\
\text { Pinnegar (2001); } \\
\text { Connelly; } \\
\text { Clandinin (1990); } \\
\text { Reed-Danahay } \\
\text { (1997). }\end{array}$ & $\begin{array}{l}\text { Base de conhecimentos. } \\
\text { Melhorar/ criticar a prática. } \\
\text { Transformação profissional } \\
\text { e pessoal. }\end{array}$ & $\begin{array}{l}\text { Investigação } \\
\text { docente. } \\
\text { Autobiografia. } \\
\text { Investigação } \\
\text { narrativa. } \\
\text { Auto estudo. }\end{array}$ \\
\hline $\begin{array}{l}\text { 2. Desde dentro } \\
\text { em colaboração } \\
\text { com colegas }\end{array}$ & Saavedra (1996) & $\begin{array}{l}\text { Base de conhecimentos. } \\
\text { Melhorar/ criticar a prática. } \\
\text { Transformação profissional/ } \\
\text { organizacional. }\end{array}$ & $\begin{array}{l}\text { Grupos de } \\
\text { investigação. } \\
\text { Equipes. } \\
\text { Grupos feministas. }\end{array}$ \\
\hline $\begin{array}{l}\text { 3. Desde dentro } \\
\text { em colaboração } \\
\text { com facilitador }\end{array}$ & $\begin{array}{l}\text { Herr; Anderson } \\
\text { (2005) }\end{array}$ & $\begin{array}{l}\text { Base de conhecimentos. } \\
\text { Melhorar/ criticar a prática. } \\
\text { Transformação profissional/ } \\
\text { organizacional. }\end{array}$ & $\begin{array}{l}\text { Oficinas de } \\
\text { educadores com } \\
\text { facilitador. }\end{array}$ \\
\hline $\begin{array}{l}\text { 4. Colaboração } \\
\text { recíproca (equipe } \\
\text { de dentro e de } \\
\text { fora) }\end{array}$ & $\begin{array}{l}\text { Herr; Anderson } \\
\text { (2005); } \\
\text { Bartunek; Louis } \\
\text { (1996). }\end{array}$ & $\begin{array}{l}\text { Melhorar/ criticar a prática. } \\
\text { Transformação profissional/ } \\
\text { organizacional. }\end{array}$ & $\begin{array}{l}\text { Investigação- ação } \\
\text { colaborativa, } \\
\text { participativa. }\end{array}$ \\
\hline
\end{tabular}




\begin{tabular}{|l|l|l|l|}
\hline $\begin{array}{l}\text { 5. Desde fora em } \\
\text { colaboração com } \\
\text { os de dentro }\end{array}$ & $\begin{array}{l}\text { Herr; Anderson } \\
\text { (2005); } \\
\text { Bradbury; Reason } \\
\text { (2001). }\end{array}$ & $\begin{array}{l}\text { Base de conhecimentos. } \\
\text { Melhorar/ criticar a prática. } \\
\text { Desenvolvimento/ } \\
\text { transformação } \\
\text { organizacional. }\end{array}$ & $\begin{array}{l}\text { Agente de troca. } \\
\text { Consulta da } \\
\text { aprendizagem } \\
\text { organizacional. } \\
\text { Investigação } \\
\text { temática (Freire). }\end{array}$ \\
\hline $\begin{array}{l}\text { 6. O investigador } \\
\text { estuda os de } \\
\text { dentro desde fora }\end{array}$ & $\begin{array}{l}\text { Campbell; Stanley } \\
\text { (1963); } \\
\text { Lincoln \& Guba } \\
\text { (1985). }\end{array}$ & Base de conhecimentos & $\begin{array}{l}\text { Investigadores } \\
\text { universitários } \\
\text { estudam } \\
\text { (desenvolvem) } \\
\text { projetos de } \\
\text { investigação-ação } \\
\text { desde fora. }\end{array}$ \\
\hline
\end{tabular}

No quadro 1 temos um contínuo de posição com o cenário de pesquisa que nos ajuda a pensar nos critérios de validade bem como nos dilemas éticos e políticos da investigaçãoação. A posição número um em contínuo corresponde ao docente que faz investigação-ação, a qual pode tomar a forma de investigação docente (HERR; ANDERSON, 2005): autobiografia ou auto/etnografia (REED-DANAHAY, 1997), auto-estudo (BULLOUGH; PINNEGAR, 2001), narrativa docente (CONNELLY; CLANDININ, 1990; SUÁREZ; OCHOA, 2005). Esta posição se refere ao docente que pesquisa sua própria prática na sua sala de aula ou ao diretor de escola que faz pesquisa sobre sua prática de gestão escolar. Os autores que citamos têm sugerido critérios de validade correspondentes às diferenças entre as formas de pesquisa inclusas nesta posição. Este tipo de investigação pode resultar não apenas na generalização do conhecimento local e público, mas também no desenvolvimento profissional e pessoal do docente.

Seguindo o contínuo chegamos à posição de número dois, a qual consiste em um grupo de docentes que deve incluir também o aluno e membros da comunidade (ver Kaplun, 2004 para um exemplo de IAP com jovens). Este tipo de investigação colaborativa, além de gerar conhecimentos e promover o desenvolvimento pessoal e profissional, pode resultar na aprendizagem e às vezes na transformação organizacional (por exemplo, ver Golzman, López e Grupo SIMA).

A posição três (e às vezes até a quatro) é uma variante da posição anterior que inclui um facilitador que não seja um membro da escola. O modelo de oficinas de educadores cabe dentro desta posição. Quando as oficinas são formadas por docentes de uma mesma escola, existe maior possibilidade de aprendizagem ou transformação organizacional. Achilli (2000) descreve os momentos principais das oficinas de educadores: 
O que nós denominamos de "Oficina de Educadores" implica em uma modalidade grupal de trabalho orientada tanto para o aperfeiçoamento docente quanto para a investigação socioeducativa, um espaço de coparticipação entre docentes em atividade e grupo de investigação socioeducativa em torno de uma problemática socioeducativa combinada coletivamente (p. 58).

A posição quatro representa um grupo composto tanto por docentes quanto por investigadores universitários. Como nas oficinas descritas por Elena Achilli, na sua forma mais autêntica, os docentes e universitários negociam e investigam juntos sobre perguntas e dilemas de interesse mútuo. Este tipo de grupo tem de negociar continuamente suas relações de poder e aproveitar os conhecimentos especializados tanto dos docentes como dos investigadores universitários. Esta é a forma ideal, porém mais rara de se alcançar, da investigação-ação participativa. A forma mais emancipatória é a que descreve Paulo Freire, e consiste em elaborar junto com as comunidades de base os temas geradores. Temas que conduzem a uma investigação que ilumina relações de poder na sociedade e orienta a uma possível transformação social. Em teoria, este método de coaprendizagem pertence à posição quatro, mas na prática tende a vacilar entre a posição quatro e a cinco.

A mais típica da investigação-ação participativa (IAP) é a posição cinco, na qual o investigador profissional - que provem de uma universidade ou de alguma agência governamental ou não-governamental -, chega a um cenário social não para trabalhar em equipe com uma comunidade ou grupo de docentes, mas com a intenção de "incluir" os participantes em alguns aspectos do projeto.

Finalmente, a posição seis representa a posição neopositivista, na qual o investigador é "uma mosca na parede", observando um cenário social de fora e tentando atingir a invisibilidade.

As reflexões de Sverdlick I ${ }^{\mathrm{vi}}$, capturam as sutilezas de como a partir da posição do Ministério da Educação, com suas relações de poder implícitas nas transações com as escolas, tornou-se difícil a criação de grupos de autoavaliação compostos por funcionários e docentes. Cada escola tinha um contexto micropolítico distinto e a falta de normas de colegiado nas escolas dificultou aos docentes compartirem, sobretudo, os êxitos e fracassos na aula. Como indica Sverdlick, o ensino 
(...) não é objeto de conversação. É o espaço de resguardo de cada docente de forma individual, seu espaço íntimo que compartilha como algo pessoal e que não é motivo de trabalho. (...) Para que se construa como espaço de diálogo, é necessário que o ensino seja considerado um assunto público. E isso implica uma mudança de posição individual e coletiva do docente para uma ideia de trabalho coletivo.

Como também indica Sverdlick, I., a quantidade de tempo requerida para alcançar a confiança e negociar diferenças de status e cultura profissional entre os funcionários e docentes dificilmente é disponibilizada, dada as circunstâncias de trabalho de uns e outros.

\section{A investigação-ação: conhecimento e interesse}

Os docentes estão imersos em um mundo de práticas reificado e naturalizado onde se constrói o sentido comum da prática docente. O docente não tem acesso direto à "realidade de sua prática". Ele, como observador que chega de fora, também interpreta sua realidade, mas o faz a partir de uma posição a qual Geertz (1983) chama de "mais próxima da própria experiência". Por isso, a investigação-ação, para simplesmente não reproduzir práticas que constituem o status quo, necessita de algum mecanismo para que o docente possa problematizar essa realidade naturalizada. A problemática das fontes de distorção na investigação social tem sido um dilema para filósofos, desde as sombras na caverna de Platão, o subconsciente de Freud, a falsa consciência de Marx, até a hegemonia de Gramsci. Ainda que os sociólogos falem muito da reflexividade, existem poucos exemplos de como ela é levada a cabo na investigação-ação.

O filósofo mais citado neste sentido é Jürgen Habermas (1971), o qual disse que o conhecimento nunca é neutro. Segundo Habermas, o conhecimento e os interesses humanos são inseparáveis. Não está de acordo com as afirmações dos objetivistas conforme as quais o conhecimento válido só pode ser gerado com as metodologias empírico-analíticas. Esses métodos de investigação procuravam separar o que consideravam os rumos do pesquisador, do objeto/sujeito da pesquisa. Sem dúvida, Habermas insistiu que tal separação era uma ilusão. Ele sustentou que na medida em que o conhecimento é gerado com o interesse da mente e que ambos se ligam, então não podem ser separados. Em sua refutação à ideia de que o objetivismo seja o único caminho válido até o conhecimento, apresenta três "interesses 
distintos" do pesquisador na busca da geração do conhecimento: técnico, prático e emancipador. Cada um destes interesses estabelece uma orientação e uma metodologia associada à investigação.

O interesse técnico foca no desejo humano de controlar o meio natural e social. O conhecimento produzido com esta orientação assume historicamente uma postura "desinteressada" em relação ao assunto que investiga, e o conhecimento gerado adquire a forma de instrumentalização e explicações causais. O interesse prático se refere a uma orientação que busca conhecer através da interpretação. O pesquisador na busca do interesse prático emprega as metodologias interpretativas - principalmente, a interpretação hermenêutica - em um esforço por alcançar a compreensão de uma situação. Por isso, a compreensão interpretativa pretende gerar conhecimentos que informem e guiem o juízo prático. Os métodos que se associam ao interesse prático incluem métodos hermenêuticos tais como análise textual, conversacional e do discurso, assim como métodos etnográficos, narrativos e outros métodos qualitativos.

Um interesse emancipador se baseia no potencial humano e se centra no funcionamento da ideologia e do poder dentro das organizações e da sociedade. A finalidade desse tipo de investigação é a emancipação dos participantes dos ditos ou das obrigações da tradição, do precedente, do hábito, da coerção ou do autoengano (CARR; KEMMIS, 1986). Supõe-se que estas últimas formam uma parte invisível da estrutura normativa das organizações e que, através de processos de autorreflexão crítica, podemos torná-las visíveis para examiná-las, o que conduz, em última instância, à transformação.

Habermas não é o único filósofo a propor formas de reflexão crítica. No contexto latino-americano, Paulo Freire pode ser uma menção mais próxima. Seja como for, é importante sublinhar que, sem nenhuma maneira de problematizar uma realidade docente naturalizada, a investigação docente corre o risco de justificar e reproduzir práticas que podem manter um status quo inaceitável.

Daniel Suárez (2007) elabora uma forma de reflexão docente através da documentação pedagógica, utilizando narrativas docentes e um processo sistemático de reescritura. Diferentemente da metodologia biográfica de Rivas Flores (2007), na proposta de Suárez, os docentes narram suas experiências sem a mediação direta de outros investigadores:

(...) Ao contar suas histórias de ensino, os docentes autores descobrem sentidos pedagógicos parcialmente ocultos ou ignorados, questões 
pedagógicas ainda não nomeadas ou nomeadas de forma pouco adequadas. E quando conseguem se posicionar como arqueólogos ou antropólogos de sua própria prática pedagógica, quando conseguem se distanciar dela para tornála objeto de pensamento e podem documentar alguns de seus aspectos e dimensões não documentadas, se dão conta do que sabem e do que não conhecem ou não podem nomear. Convertem sua consciência prática em discursiva através da narração de sua prática, colocam-na em tensão, compõem-na e recompõem-na, objetivam-na, fixam-na em escritura, comunicam-na, criticam-na.

Sem dúvida, ainda falta uma documentação mais exaustiva dos processos de reflexão crítica tanto na investigação-ação como na investigação narrativa.

\section{Em síntese...}

Em geral, a investigação docente tem como propósito principal a reflexão e desenvolvimento profissional mais do que a geração de conhecimentos para disseminar para além do cenário local. Isto é, em parte, porque as instituições educativas não têm nem condições de trabalho, nem um sistema de incentivos que favoreça a investigação docente com fins de difusão, o que requer a preparação e publicação de um informe. Ademais, poucos docentes têm a sofisticação metodológica requerida para recolher e analisar dados, ao menos na forma exigida pelos cientistas sociais. Suárez e Connely e Clandinin (Op. cit.) sugerem uma metodologia das humanidades, a investigação narrativa, que de alguma maneira é afim à forma como os docentes difundem conhecimentos entre eles. Segundo Brito e Suárez (2001), a narrativa conta:

Aquilo que um docente vive e interpreta de uma situação de ensino e de aprendizagem que ele mesmo planejou, desenvolveu e avaliou. Não obstante, quando um docente narra, elege certos aspectos, seleciona e enfatiza outros, omite, estabelece uma sequência aos momentos da história de um modo particular. Desta maneira, a partir dessas decisões tomadas pelo docente narrador, o relato transmite e ressignifica o sentido que o autor outorga a sua vivência. Ademais, convida a que outros docentes se apropriem do relatado de um modo pessoal no qual as próprias experiências se enredam com as transmitidas, (p. 5).

Apesar das dificuldades, muitos docentes têm encontrado, sobretudo nos métodos etnográficos e na narração de experiências, formas de documentar e repensar não apenas suas 
práticas, mas também seu contexto sociocultural e econômico. Estão surgindo - tanto na Argentina como nos Estados Unidos - uma quantidade crescente de livros e artigos publicados por docentes. Na Argentina, a impressionante produção do professor Luis Iglesias serve de exemplo para professores que têm paixão em participar nas conversações sobre formação docente e as políticas educativas.

\section{REFERÊNCIAS:}

ACHILLI, E. Investigación y formación docente. Rosario: Laborde Editor, 2000.

ANDERSON, G. L; HERR, K; NIHLIN, A. Studying your own school: A guide to qualitative practitioner research. Thousand Oaks, CA: Corwin Press, 1994.

ANDERSON, G, L; JONES, F. Knowledge generation in education administration from the inside-out: the promise and perfils of site-based, administrator research. Educational Administration Quartely, 36 (3), 428- 464, 2000.

ANZALDÚA, G. La frontera/ bordlands: the new Mestiza. San Francisco: Aunt Lute Books, 1999.

ARGYRIS; SCHÖN. Organizational Learning: a Theory of Action perspective. AddisonWesley Publishing Company, Inc., 1978.

BARTUNEK, J.; LOUIS, J. Problema de la investigación participante y la transformación de la escuela. Cuaderno de Formación Docente. N.5, Universidad Nacional de Rosario, 1988.

BONE, D. Quality of management is collegiate management: improving practice in a special school. In: LOMAX, P. (ed.). Quality management of education: sustaining the vision through actions research, p. 166-184. Londres: Routledge, 1996.

BRADBURY, H.; REASON, P. Conclusion: Broadening the bandwidth of validity: Issues and choice-points for improving the quality of action research. In: REASON, P.;

BRADBURY, H. (eds.). Handbook of action research: Participative inquiry \& practice. Londres: Sage, 2001.

BRITO, A.; SUÁREZ, D. “Documentar la enseñanza”. Revista el Monitor, n.4, Buenos Aires, Ministério de Educación, 2001.

CAMPBELL, D. T.; STANLEY, J. C. Experimental and quasi-experimental designs for research. Dallas: Houghton Mifflin, 1963. 
CARR, W; KEMMIS, S. Teoría crítica de la educación: la investigación-acción en la formación del profesorado. Barcelona: Martínez Roca, 1988.

CLANDININ, J.; CONNELLY, M. Teacher's professional knowledge landscapes. New York: Teachers College Press, 1995.

COCHRAN-SMITH, M.; LYTLE, S. Teacher research: the question that persists. International journal of leadership in education, 1 (1), 19-36, 1998.

COLLINS, P. H. Black feminist thought: knowledge, consciousness, and the politics of empowerment. New York: Routledge, 1990.

CONNELLY, F. M; CLANDININ, J. Stories of experience and narrative inquiry. Educational Reseacher, 19 (5), p. 2-14, 1990.

CUNNINGHAM, J. B. Gathering data in a changing organization. Human relations, 36 (5), 403-420, 1983.

ELLIOTT, J. B. Gathering data in a changing organization. Human Relations, 36 (5), 403420, 1983.

ENRÍQUEZ, P. Modalidades y discusiones en torno a 1 noción de docente investigador. Universidad Católica de Córdoba, REDUC, 2004. Disponível em: <www.uccor.edu.ar/paginas/REDUC/romero.enriquez.pdf>. Aceso em: 25 jul. 2016.

FALS BORDA, O. Acción y conocimiento. Bogotá: Cinep, 1991.

FENSTERMACHER, G. The knower and the known: the nature of knowledge in research on teaching. In: DARLING-HAMMOND, L (Ed.). Review of Research in Education, 20, 3-56, 1994.

FLORES, I. R. Vida, experiencia y educación: la biografia como estrategia de conocimiento. IN: SVERDLICK, I. (comp.). La investigación educativa: una herramienta de conocimiento y de acción. Buenos Aires: Noveduc, 2007.

FREIRE, P. Pedagogía del Oprimido. Madrid: Siglo XXI, 1968.

GEERTZ, C. Local knowledge: Further essays in interpretative antrophology. New York: Basic Books, 1983.

GIROUX, H. Los profesores como intelectuales: hacia una teoria crítica de la enseñanza. Barcelona: Paidós, 1990.

GOLZMAN, G.; LÓPEZ, D.; Grupo SIMA (Coords.). Atención: maestros trabajando. Experiencias participativas em la escuela. Buenos Aires: Coquena, 1989.HABERMAS, J. Conocimiento y interés: ciencia y técnica como ideologia. Madrid: Tecnos, 1971. 
HABERMAS, J. Conocimiento e interés: Ciencia y técnica como ideología. Madrid: Tecnos, 1994.

HERR, K; ANDERSON, G. L. The action research dissertation: a guide for students and faculty. Thousand Oaks: Sade Pub. 2005.

HUBERMAN, M. Focus on research moving mainstream: Taking a closer look at teacher research. Language Arts, 73 (2), 124-140, 1996.

KAPLUN, G. Culturas juveniles y educación. Pedagogía crítica, estúdios culturales e investigación participativa. En: Los jóvenes: múltiples miradas. Neuquén: UNC, 2004.

LATHER, P. Issues of validity in openly ideological research: between a rock and a hard place. Interchange, 17, 63-84, 1986.

LATORRE, A. La investigación-acción: conocer y cambiar la práctica educative. Barcelona: Graó, 2003.

LOMAX, P; WOODWARD, C; PARKER, Z. How can we help educational managers establish and implement effective "critical"friendships? In: LOMAX, P. (ed.). Quality management of education: sustaining the vision through actions research, p. 166-184. Londres: Routledge, 1996.

LÓPEZ GORRIZ, I. La investigación-acción como metodología de teorización y formación del profesor desde su práctica. Revista de Investigación Educativa, 71-92, 1993.

MARTínEZ, M. M. La investigación-acción en el aula. Agenda Académica, 7 (1), 27-39, 2000 .

MYERS, M. The teacher-reseacher: how to study writing in the classroom. Urbana, IL, National Council of Teachers of English, 1985.

OLSON, M. W. La investigación-acción entra al aula. Buenos Aires: Aique, 1991.

PÉREZ GÓMEZ, A. El profesor como profesional autónomo que investiga reflexionando su propria práctica. In: ELLIOT, J. La investigación-acción en educación. Madrid: Morata, 1990.

REED-DANAHAY, D. (Ed.). Auto/ethnography: rewriting the self and the social. Nueva York: Berg, 1997.

RICHARDSON, V. Conducting research on practice. Educational Researcher, 23 (5), 5-10, 1994.

SAAVEDRA, E. Teacher study groups: contexts for transformative learning and action. Theory into Practice, 35 (4), 271-277, 1996. 
SANTILLÁN, M. Protagonismo docente y desarollo profesional: una perspectiva desde la pedagogía del educador argentino Luis F. Iglesias. Tesis doctoral. University of New Mexico, 2002.

SIRVENT, M. T. La investigación participativa aplicada a la renovación curricular. Revista Latinoamericana de innovaciones educativas, 11-74, 1993.

SUÁREZ, D. H. Docentes, narrativa e investigación educativa: La documentación narrativa de lãs práticas docentes y La indagación pedagógica Del mundo y lãs experiencias escolares. In: SVERDLICK, I. (comp). La investigación educativa: Uma herramienta de conocimiento y de acción. Buenos Aires: Noveduc, 2007.

SUÁREZ, D; OCHOA, L. La documentación narrativa de experiências pedagógicas: uma estratégia para la formación docente. Buenos Aires: Ministerio de Educación, Ciencia y Tecnología, 2005.

SVERDLICK, I. La investigación educativa como instrumento de acción, de formación y de cambio. In: SVERDLICK, I. (comp.). La investigación educativa: Uma herramienta de conocimiento y de acción. Buenos Aires: Noveduc, 2007.

ZEICHNER, K. El maestro como profesional reflexivo. Cuadernos de Pedagogía, n. 220, monográfico "El profesorado". Barcelona, 44-49, 1993.

\footnotetext{
' Publicado, originalmente, como capítulo de livro em SVERDLICK, I. (comp.). La investigación educativa: una herramienta de conocimiento y de acción. Buenos Aires: Noveduc, 2007. Tradução de Tiago Ribeiro, doutorando do Programa de Pós-graduação em Educação da UNIRIO, professor do Colégio de Aplicação do Instituto Nacional de Educação de Surdos e integrante da Rede de Formação Docente: Narrativas \& Experiências (Rede Formad).

ii Professor da Faculdade de Educação, New York University (NYU) e do Mestrado e Doutorado em Gestão Escolar e Política Educativa. Com Kathryn Herr publicou dois livros sobre a investigação-ação: The Action Research Dissertation: A Guide for Students and Faculty, e Studying your own school: An educator's guide to practitioner action research.

iii Docente e trabalhadora social. Professora na Faculdade de Educação e Serviços Sociais em Montclair State University em Montclair, New Jersey.

iv Grifo dos tradutores.

" No original [em espanhol], o autor usa o termo "testimonio docente". Todavia, optamos por traduzir como "relato docente", pois este é o termo que vem sendo usado em textos que tratam do tema, em português.

vi Refere-se ao texto La investigación educativa como instrumento de acción, de formación y de cambio, primeiro capítulo do livro no qual o artigo aqui traduzido foi publicado pela primeira vez, em espanhol.
} 